\title{
Behaviour Change
}

http://journals.cambridge.org/BEC

Additional services for Behaviour Change:

Email alerts: $\underline{\text { Click here }}$

Subscriptions: $\underline{\text { Click here }}$

Commercial reprints: $\underline{\text { Click here }}$

Terms of use : $\underline{\text { Click here }}$

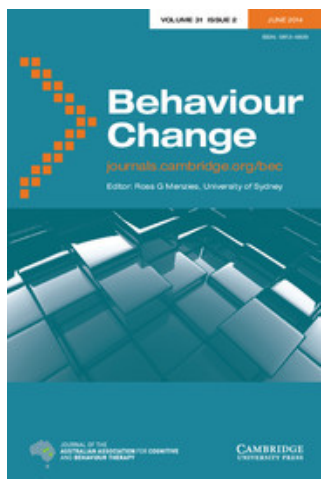

\section{Processing of Emotional Faces in Children and Adolescents With Anxiety Disorders}

Kristy E. Benoit, Richard J. McNally, Ronald M. Rapee, Amanda L. Gamble and Amy L. Wiseman

Behaviour Change / Volume 24 / Issue 04 / November 2007, pp 183 - 194

DOI: 10.1375/bech.24.4.183, Published online: 22 February 2012

Link to this article: http://journals.cambridge.org/abstract_S0813483900002072

How to cite this article:

Kristy E. Benoit, Richard J. McNally, Ronald M. Rapee, Amanda L. Gamble and Amy L. Wiseman (2007). Processing of Emotional Faces in Children and Adolescents With Anxiety Disorders. Behaviour Change, 24, pp 183-194 doi:10.1375/bech.24.4.183

Request Permissions : $\underline{\text { Click here }}$ 
Copyright by the Cambridge University Press. Kristy E. Benoit, Richard J. McNally, Ronald M. Rapee,

Amanda L. Gamble and Amy L. Wiseman (2007). Processing of Emotional Faces in Children and Adolescents

With Anxiety Disorders. Behaviour Change, 24, pp. 183-194 doi:10.1375/bech.24.4.183

\title{
Standard Papers
}

\section{Processing of Emotional Faces in Children and Adolescents With Anxiety Disorders}

\author{
Kristy E. Benoit and Richard J. McNally \\ Harvard University, United States of America
}

Ronald M. Rapee and Amanda L. Gamble

Macquarie University, Australia

Amy L. Wiseman
Allegheny College, United States of America

The purpose of this study was to test whether children and adolescents with anxiety disorders exhibit selective processing of threatening facial expressions in a pictorial version of the emotional Stroop paradigm. Participants named the colours of filters covering images of adults and children displaying either a neutral facial expression or one displaying the emotions of anger, disgust, or happiness. A delay in naming the colour of a filter implies attentional capture by the facial expression. Anxious participants, relative to control participants, exhibited slower colour naming overall, implying greater proneness to distraction by social cues. Children exhibited longer colour-naming latencies as compared to adolescents, perhaps because young children have a limited ability to inhibit attention to distracting stimuli. Adult faces were associated with slower colour naming than were child faces, irrespective of facial expressions in both groups, possibly because adults provide especially salient cues for children and adolescents. Inconsistent with prediction, participants with anxiety disorders were not slower than healthy controls at naming the colours of filters covering threatening expressions (i.e., anger and disgust) relative to filters covering faces depicting happy or neutral expressions.

$\mathrm{B}$ ecause attentional capacity is limited, a person can attend to only a subset of stimuli at any given time. A bias for selectively attending to threatening cues should increase a person's likelihood of experiencing anxiety and perhaps developing anxiety disorders. Confirming this intuition, cognitive psychology experiments have shown that adults with anxiety disorders are characterised by an attentional bias for processing threatening information (For a review, see Harvey, Watkins, Mansell, \& Shafran, 2004, pp. 25-70). For example, in the emotional Stroop task (Williams, Mathews, \& MacLeod, 1996), participants are shown words of varying emotional significance, and are asked to name the colours in which the words appear while ignoring the meanings of the words. Delays in colour-naming occur when the meaning of

Address for correspondence: Kristy E. Benoit, Child Study Center, Department of Psychology, Virginia Tech, 460 Turner Street, Suite 207, Blacksburg, VA 24060 USA. E-mail: benoit@vt.edu 
the word captures the participant's attention despite his or her effort to attend to the colour of the word. Most experiments have shown that adults with anxiety disorders take longer to name the colours of words related to their threat-related concerns than to name the colours of other emotional or neutral words, and take longer to name the colours of threat words than do psychiatrically healthy control participants (Williams et al., 1996). Although debate continues about the mechanisms driving the emotional Stroop effect, it remains among the most robust cognitive bias effects in the adult anxiety disorders field.

Emotional Stroop studies involving anxious children have revealed mixed results. Relative to control participants, spider-fearful children have taken longer to name the colours of spider words (Martin, Horder, \& Jones, 1992) and the colours of line drawings of spiders (Martin \& Jones 1995). Adolescent survivors of a shipwreck who developed posttraumatic stress disorder (PTSD) exhibited delayed colour naming of trauma-related words (Thrasher, Dalgleish, \& Yule, 1994), as did children who developed PTSD after being either physically or sexually abused (Dubner \& Motta, 1999). Relative to control participants, children and adolescents (aged 9-17 years) with PTSD following either road traffic accidents or exposure to violence exhibited slower colour naming for trauma words than for neutral words (Moradi, Taghavi, Neshat-Doost, Yule, \& Dalgleish, 1999).

Children and adolescents with generalised anxiety disorder (GAD) exhibit slower colour naming of negative words, especially threat-related ones, than of positive or neutral words (Taghavi, Dalgleish, Moradi, Neshat-Doost, \& Yule, 2003).

However, several researchers have failed to replicate the anxiety-linked Stroop effect in children. For example, nonanxious children have exhibited just as much of an effect for threat words as have anxious children in some experiments (Kindt, Bierman, \& Brosschot, 1997; Kindt, Brosschot, \& Everaerd, 1997). A pictorial version of the spider Stroop (naming colours of backgrounds against which spider pictures appeared) did not reveal a fear-related effect in children aged 8-11 (Kindt, van den Hout, de Jong, \& Hoekzema, 2000).

More recent studies concerning the dot probe task have also failed to reveal an attentional bias toward threat in anxious children and adolescents. Adolescents with generalised anxiety disorder showed a greater attentional bias away from angry faces than did controls (Monk et al., 2006), and children who had been physically or sexually abused and/or neglected demonstrated an attentional bias away from threatening faces (Pine et al., 2005).

The purpose of the present experiment was to test whether children and adolescents with anxiety disorders, relative to healthy control participants, exhibit delayed colour naming of threat-related faces of children and adults in a variant of the pictorial emotional Stroop paradigm. Modifying our previous version of the pictorial Stroop (Constantine, McNally, \& Hornig, 2001), we asked participants to name the colours of filters covering pictures of adults and children displaying either an emotionally neutral facial expression or an expression depicting anger, disgust, or happiness. Psychologists have increasingly utilised facial expressions of emotion as ecologically valid stimuli having potential evolutionary significance in attentional bias research on adults (e.g., Mansell, Clark, Ehlers, \& Chen, 1999). Moreover, although researchers have increasingly utilised facial expressions of emotion in attentional bias studies involving adults (e.g., Mogg, Philippot, \& Bradley, 2004), they have only recently begun to use these cues with children. Pollack and Tolley-Schell (2003) found that physically abused children, aged 8 to 11 years, exhibited delayed attentional disengagement from angry facial 
expressions in a selective attention paradigm. Likewise, Hadwin et al. (2003) found that trait anxiety in children aged 7 to 10 years was related to attentional bias for schematic angry faces in a visual search paradigm. Although emotional Stroop studies in children have produced conflicting results, facial expressions of emotion may possess greater ecological validity than relatively abstract lexical threat cues.

Accordingly, we predicted that relative to control participants, those with anxiety disorders would exhibit slower colour naming of threatening faces (anger and disgust) relative to happy and neutral faces. Facial expressions of anger convey threat, whereas expressions of disgust convey contempt and rejection. We chose not to include fearful faces as they convey only indirect threat to the observer, whereas anger and disgust faces more directly communicate social threat.

\section{Method}

\section{Participants}

Patients were recruited from among those scheduled for assessment at the Child and Adolescent Anxiety Clinic at Macquarie University, Sydney, Australia.

The clinical group $(n=52)$ consisted of 37 children aged 7 to 12 years $(M=9.8$, $S D=1.6)$ and 15 adolescents aged 13 to 17 years $(M=14.6, S D=1.4)$. Twenty-two of the children were female, whereas seven of the adolescents were female. All participants met criteria for an anxiety disorder, according to the Anxiety Disorders Interview Schedule for Children and the Anxiety Disorders Interview Schedule for Parents (ADIS-C and ADIS-P; Silverman \& Nelles, 1988). Many qualified for more than one anxiety disorder, other disorders, or both. The numbers of patients meeting criteria were as follows: generalised anxiety disorder $(n=47)$, social phobia $(n=32)$, specific phobia $(n=27)$, separation anxiety disorder $(n=22)$, panic disorder $(n=3)$, obsessive-compulsive disorder $(n=3)$, anxiety disorder not otherwise specified $(n=2)$, and posttraumatic stress disorder $(n=1)$. Other comorbid diagnoses included attention deficit hyperactivity disorder $(n=9)$, oppositional defiant disorder $(n=7)$, dysthymia $(n=7)$, [major] depression $(n=6)$, enuresis $(n=2)$, conduct disorder $(n=1)$, and selective mutism $(n=1)$.

The control group $(n=46)$ consisted of 27 children aged 7 to 12 years $(M=10.3$, $S D=1.5)$ and 19 adolescents aged 13 to 15 years $(M=14.0, S D=0.88)$. Thirteen of the children were female, whereas 12 of the adolescents were female. Participants were recruited through school newsletters and community newspapers. None qualified for a current mental disorder, according to the ADIS-C and ADIS-P. Among the children, the control group $(M=10.3, S D=1.5)$ and the clinical group $(M=9.8$, $S D=1.6)$ did not differ in age, $t(62)=1.14, p=.26$. For the adolescents, there was also no difference in age, $t(22)=1.45, p=.16$, between the control group $(M=14.0$, $S D=.88)$ and the clinical group $(M=14.6, S D=1.4)$. The child control and patient groups did not differ with respect to sex ratio, $\chi^{2}(1)=.81, p=.37$, and neither did the adolescent groups, $\chi^{2}(1)=.93, p=.34$.

Participants completed the Spence Children's Anxiety Scale (SCAS; Spence, 1997, 1998) and the Strengths and Difficulties Questionnaire (SDQ; Goodman, 1997), which assesses externalising problems such as hyperactivity, inattention, conduct problems, and difficulties with peers. Parents of participants, usually mothers, completed the parent-report version of these questionnaires (SCAS-P; Nauta, Scoling, Rapee, Abbott, \& Spence, 2004; SDQ-P; Goodman, 1997). The child and parent versions of each test were highly correlated (SCAS and 


\section{TABLE 1}

Means and Standard Deviations for Psychometric Measures

\begin{tabular}{lcccccc}
\hline Measure & \multicolumn{2}{c}{ Clinical Group } & \multicolumn{2}{c}{ Control Group } & $t$ & $p$ \\
\cline { 2 - 5 } & $M$ & $S D$ & $M$ & $S D$ & & \\
\hline SCAS & 36.1 & 19.3 & 11.8 & 8.1 & 7.89 & .001 \\
SCAS-P & 34.1 & 17.0 & 8.5 & 5.6 & 9.65 & .001 \\
SDQ & 14.3 & 7.2 & 7.2 & 5.4 & 5.49 & .001 \\
SDQ-P & 15.4 & 7.3 & 4.4 & 3.8 & 9.16 & .001 \\
\hline
\end{tabular}

Note: SCAS = Spence Children's Anxiety Scale (possible range of scores: 0-114); SCAS-P = Spence Children's Anxiety Scale - Parent Version (possible range of scores: 0-114); SDQ = Strengths and Difficulties Questionnaire (possible range of scores: $0-40$ ); SDQ-P $=$ Strength and Difficulties Questionnaire-Parent Version (possible range of scores: 0-40). Because of missing data, $d f$ s were 98 for the SCAS and SDQ, and 96 for the SCAS-P and SDQ-P.

MSCAS: $r=.85, p<.001$; SDQ and MSDQ: $r=.75, p<.001)$. As evident from Table 1 , the clinical group was more symptomatic than the control group on all four measures.

\section{Apparatus and Materials}

Adult faces depicting emotions were from Matsumoto and Ekman's (1989) set, whereas child faces were from Mazurski and Bond (1993). Following Constantine et al.'s (2001) procedure, we first created grayscale images by removing colour from the original picture, and then created integrated Stroop stimuli by placing a colour filter over the grayscale image. We used Adobe Photoshop 4.0 to create the Stroop stimuli, SuperLab to present the stimuli, and PsyScript to present the child faces for the postexperimental validation of valence (see below). Stimuli appeared on a $40 \mathrm{~cm}$ (16 inch) Macintosh computer approximately $60 \mathrm{~cm}$ (24 inches) from the participant. Stroop colour-naming latencies were detected by a microphone positioned between the participant and the screen, and recorded in milliseconds by voice recognition software.

On every trial, participants saw a photograph of either an adult or a child displaying one of four expressions: anger, disgust, happiness, or neutral. For each expression in the adult group, there were two male and two female models. Each model/expression combination appeared four times, once per colour: blue, red, green, and yellow. Accordingly, there were a total of 64 trials involving adult faces, 32 female and 32 male. Four female and three male child models displayed the four expressions (some models displayed more than one expression). Each model/expression combination appeared four times, once per colour: blue, red, green, and yellow. There were a total of 48 trials involving child faces, 24 female and 24 male. Therefore, participants were exposed to a total of 112 trials.

The 112 presentations occurred in eight blocks, each block consisting of one model/expression combination (i.e. adult happy, child disgust, etc.). We chose a block design rather than random presentation because the former is more potent and sensitive to psychopathology than is the latter (Bar-Haim, Lamy, Pergamin, BakersmanKranenburg, \& van IJzendoorn, 2007; Holle, Neely, \& Heimberg, 1997;). Stimuli within each block appeared in a single, fixed random order except that neither a face nor a colour could appear more than twice in succession. The blocks themselves appeared in a different random order for each participant. 
Unlike the adult emotional faces validated by Matsumoto and Ekman (1989), the child faces of Mazurski and Bond (1993) have received less validation. Accordingly, after the Stroop task was completed, we asked participants to rate each of the child emotional faces on a seven-point scale ranging from 1 ('very, very mean') to 7 ('very, very nice'). For adolescents, we replaced the low anchor with 'very, very threatening'. For the clinical group, the mean ratings were 2.5 for anger, 2.8 for disgust, 4.0 for neutral, and 6.2 for happy. For the control group, the mean ratings were 2.9 for anger, 3.3 for disgust, 4.0 for neutral, and 5.9 for happy. Relative to the control group, the clinical group rated the anger faces as marginally more negative $(p=.072)$ and the disgust faces as significantly more negative $(p=.015)$. The ratings support the validity of the facial expressions of emotion in children and may suggest a bias in anxious participants for amplifying threat. The ratings also validate our decision to use disgust rather than fearful faces, as anxious individuals clearly find these faces either 'mean' or 'threatening'. Although no data were collected regarding social desirability, these ratings may have resulted from children and adolescents giving answers that they thought would be 'correct'.

\section{Procedure}

Participants were told to name the colour of each picture as accurately and as quickly as possible while ignoring the content of the picture. Participants received 20 practice trials naming the colours of filters covering pictures of chairs. These trials enabled the experimenter to adjust the sensitivity of the microphone to ensure detection of the child's vocal response. Participants initiated each trial by pressing the space bar. The purpose of self-pacing of stimulus presentation was to counteract fatigue. After the Stroop task, the children rated the valence of the child facial expressions. The Stroop task plus the ratings took approximately 20 minutes.

\section{Results}

Prior to data analysis, we excluded outliers, defined as response latencies less than 300 $\mathrm{ms}$ or more than $3000 \mathrm{~ms}$. This resulted in the exclusion of only $5.6 \%$ of all trials. Children in the control $(M=5.9, S D=6.3)$ and clinical $(M=6.8, S D=6.6)$ groups did not differ in their average total number of outliers, $t(62)=.56, p=.58$. Adolescents in the control group $(M=4.5, S D=6.2)$ also did not differ in this regard to adolescents in the clinical group $(M=6.1, S D=6.7), t(32)=.75, p=.46$.

Mean response latencies as a function of status (clinical versus control), age group (child versus adolescent), model (adult versus child), and emotion (anger, disgust, neutral, happy) are shown in Tables 2 and 3 . These data were submitted to a 2 (status) $\times 2$ (age group) $\times 2$ (model) $\times 4$ (emotion) analysis of variance (ANOVA) with repeated measurement on the second, third, and fourth variables.

The clinical group exhibited longer colour-naming latencies than did the control group, $F(1,94)=10.53, p=.002$, children exhibited longer colour-naming latencies as compared to adolescents, $F(1,94)=8.94, p=.004$, and adult models provoked longer latencies than did child models, $F(1,94)=192.06, p<.001$.

There was also a 2-way interaction for model $\times$ emotion, $F(1,94)=3.79, p=$ .01 , which proved to be a cubic contrast, $F(1,94)=7.04, p=.009$. Paired sample $t$ tests showed that participants were slower on adult anger faces as compared to adult disgust faces, $t(95)=2.04, p=.044$. For child models, happy faces provoked less 
Kristy E. Benoit, Richard J. McNally, Ronald M. Rapee, Amanda L. Gamble and Amy L. Wiseman

\section{TABLE 2}

Mean Response Latencies as a Function of Status, Model, and Emotion in Children

\begin{tabular}{lcccc}
\hline & \multicolumn{2}{c}{ Clinical } & \multicolumn{2}{c}{ Control } \\
\cline { 2 - 5 } Stimulus & $M$ & $S D$ & $M$ & $S D$ \\
\hline Adult model & & & & \\
Anger & 982 & 231 & 826 & 174 \\
Disgust & 932 & 225 & 785 & 159 \\
Happy & 977 & 228 & 791 & 141 \\
Neutral & 970 & 204 & 805 & 135 \\
Child model & & & & \\
Anger & 855 & 303 & 656 & 192 \\
Disgust & 823 & 237 & 690 & 194 \\
Happy & 786 & 240 & 615 & 179 \\
Neutral & 819 & 263 & 682 & 201 \\
\hline
\end{tabular}

Note: Data are in milliseconds.

colour-naming delay than did either angry, $t(95)=2.7, p=.008$, disgust, $t(1,94)=$ $2.60, p=.01$, or neutral faces, $t(95)=3.0, p=.003$.

The 4-way interaction for model $\times$ emotion $\times$ status $\times$ age group closely approached significance, $F(1,94)=2.53, p=.06$, and further investigation revealed a linear contrast in this interaction, $F(1,94)=7.45, p=.008$. Given the difficulty in interpreting 4-way interactions, we decided to perform two separate 2 (status) $\times 2$ (model) $\times 4$ (emotion) ANOVAs, one for children and one for adolescents. We found that similar to our first analysis, clinical children had slower responses than control children, $F(1,62)=12.34, p<.001$, and children were slower on adult faces as com-

\section{TABLE 3}

Mean Response Latencies as a Function of Status, Model, and Emotion in Adolescents

\begin{tabular}{lcccc}
\hline & \multicolumn{2}{c}{ Clinical } & \multicolumn{2}{c}{ Control } \\
\cline { 2 - 5 } Stimulus & $M$ & $S D$ & $M$ & $S D$ \\
\hline Adult model & & & & \\
Anger & 835 & 184 & 735 & 137 \\
Disgust & 843 & 164 & 735 & 99 \\
Happy & 823 & 159 & 757 & 117 \\
Neutral & 791 & 203 & 732 & 122 \\
Child model & & & & \\
Anger & 609 & 181 & 615 & 151 \\
Disgust & 679 & 229 & 601 & 138 \\
Happy & 615 & 163 & 578 & 155 \\
Neutral & 728 & 230 & 588 & 183 \\
\hline
\end{tabular}

Note: Data are in milliseconds. 
a.

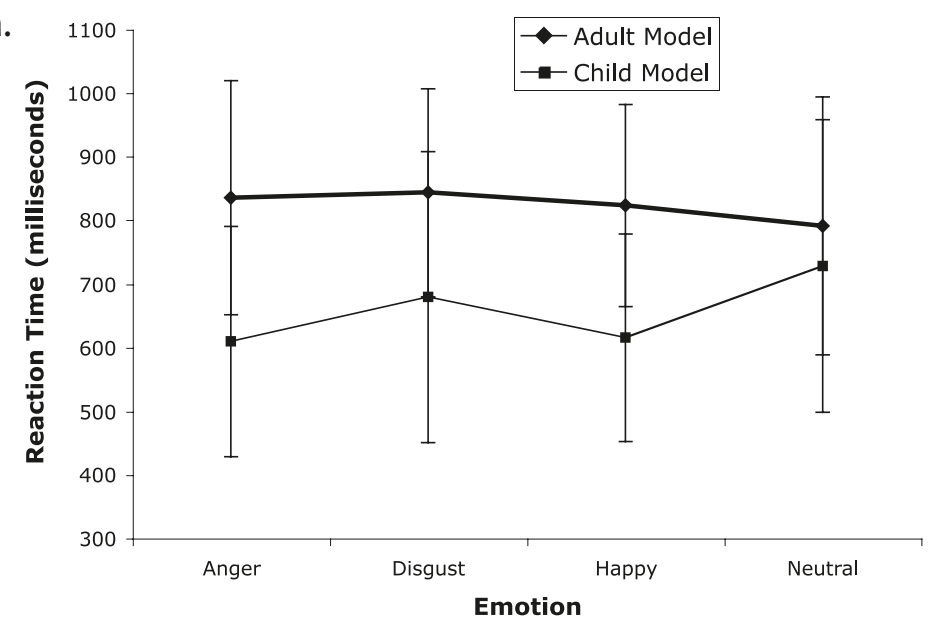

b.

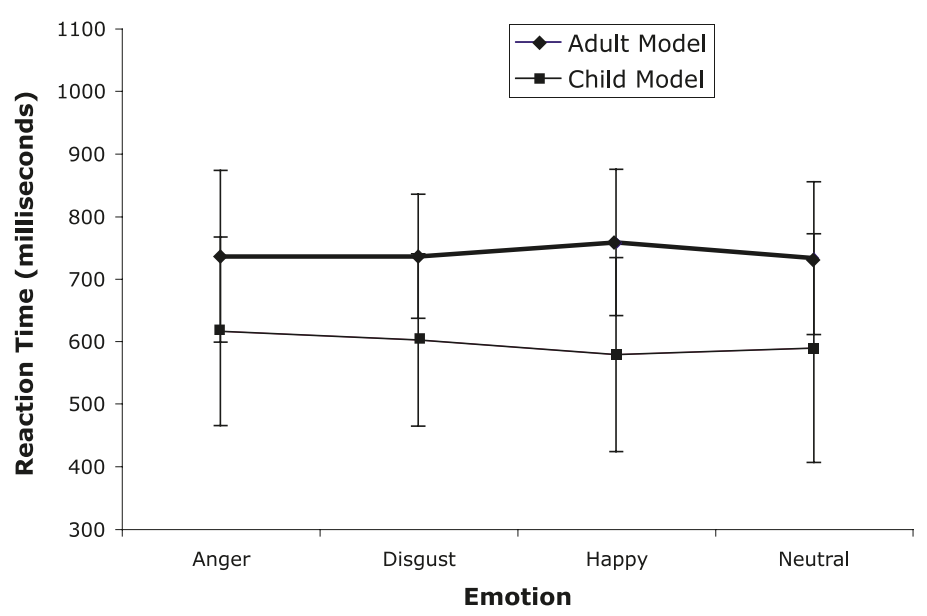

\section{FIGURE 1}

Adolescent reaction time means and standard deviations by model and emotion for (a) patients and (b) control participants.

pared to child faces, $F(1,62)=103.3, p<.001$. Two other results approached significance: emotion, $F(1,62)=2.31, p=.08$ and model $\times$ emotion, $F(1,62)=2.42, p=.07$.

In the $2 \times 2 \times 4$ ANOVA with adolescents, we again found a slower response to adult faces as compared to child faces, $F(1,32)=142.01, p<.001$. Unlike the child analysis, however, we also found significant model $\times$ emotion, $F(1,32)=3.8$, $p=.013$ and model $\times$ emotion $\times$ status, $F(1,32)=3.72, p=.014$, interactions (see Figure 1). A model $\times$ emotion cubic contrast was again revealed, $F(1,32)=4.99$, $p=.033$, which paired sample $t$ tests suggested was due to adolescents having a longer colour-naming latency with child neutral faces as compared to child happy faces, $t(33)=2.42, p=.02$.

To elucidate the 3 -way interaction in this group of adolescents, we ran a series of $2 \times 2 \times 2$ interactions involving each possible pair of emotions. We found significant 
three-way interactions with two pairs: angry/neutral, $F(1,32)=9.32, p=.005$, and happy/neutral, $F(1,32)=5.43, p=.03$. Paired sample $t$ tests showed that clinical adolescents, unlike control adolescents, were slowed by neutral child faces as compared to angry child faces $t(33)=2.60, p=.02$, and as compared to happy child faces, $t(33)=2.83, p=.013$.

\section{Discussion}

Several conclusions emerged from our study. First, like adults with anxiety disorders (Williams et al., 1996), anxious children and adolescents exhibited slower colour-naming latencies overall relative to healthy control participants. This finding suggests that young patients with anxiety disorders are more easily distracted by task-irrelevant stimuli than are their healthy peers. This finding is consistent with other studies showing general processing deficits in anxious children (Kindt et al., 2000; Kusche, Cook, \& Greenberg, 1993; Morren, Kindt, van den Hout, \& van Kasteren, 2003). Alternatively, this finding may indicate that anxious individuals are especially hesitant about responding. Such a cautious response style would slow responding to all stimuli, irrespective of emotional valence.

Second, children exhibited longer colour-naming latencies as compared to adolescents. As noted by Vasey and MacLeod (2001), young children have a limited ability to inhibit attention to distracting stimuli, and tasks such as the present one, which involve integrated stimuli, may especially tax this capacity.

Third, both anxious and control children and adolescents exhibited longer colour-naming latencies for adult faces than for child ones. This suggests that adults are especially salient cues for children and adolescents in general. Perhaps it is more difficult for youth to identify emotions on adult faces than on those of their peers.

Fourth, both groups exhibited shorter colour-naming latencies for adults displaying disgust faces as compared to anger faces. They were also faster when children displayed happy expressions relative to neutral, disgust, or angry expressions. That is, neutral expressions were functionally indistinguishable from faces expressing disgust or anger in children.

When children and adolescents were analysed separately, we failed to confirm that anxious children are characterised by disproportionately long colour-naming latencies for threat faces - those expressing either disgust or anger. This runs counter to most published research on anxious adults (Williams et al., 1996), but it is in accordance with Vasey and MacLeod's (2001) assertion that younger children do not often show an attentional bias for threatening information.

Anxious adolescents similarly did not show an attentional bias for anger and disgust faces, but they did take significantly more time to colour-name child neutral faces as compared to child anger and happy faces. Some researchers have found that anxious individuals exhibit an attentional bias away from faces depicting anger, sadness, disgust, or fear (Mansell et al., 1999; Monk et al., 2006; Pine et al., 2005) and this is what we have seen with the adolescent group and child anger faces. The fact that anxious adolescents also exhibited a bias away from happy child faces is surprising and merits future attention.

According to Vasey and MacLeod (2001), anxious children may display a bias toward negative interpretations of ambiguous stimuli. Although participants did not disproportionately rate child neutral faces as negative, perhaps anxious adolescents interpreted them as being negative in the course of the colour-naming 
task, and that was why child neutral faces produced significantly more interference than child anger and happy faces. Also, anxious adolescents may be slower to respond in the face of ambiguity.

It is important to note the significance of developmental factors in the present study. Although attentional biases did not occur in the anxious child group, they did in the anxious adolescent group. This accords with research showing that developmental issues are critical in assessing attentional biases in children and adolescents (Bar-Haim et al., 2007; Vasey \& MacLeod, 2001).

Why did expressions of anger and disgust fail to slow colour naming, especially among children and adolescents with anxiety disorders? Indeed, although the emotional Stroop sometimes fails to distinguish nonclinically anxious individuals from nonanxious ones, our anxious participants had sufficiently severe anxiety disorders as to warrant treatment. Accordingly, insufficient severity of anxiety seems an unlikely explanation for the absence of the predicted disorder-linked emotional Stroop effect.

Further, although our sample size was only sufficient to detect a moderate effect of size difference between groups $(d=.28)$ with reasonable power (i.e., .80; Erdfelder, Faul, \& Buchner, 1996), the study group was considerably larger than in most studies showing an emotional Stroop effect in adults.

Despite their seeming ecological relevance, facial expressions of disgust and anger may have failed as potent threat stimuli. On the other hand, anxious participants did interpret these faces as threatening on the rating task, but only in child models, as adult faces were not rated.

Some studies suggest that facial expressions of fear may be especially potent cues for activating the amygdala (e.g., Whalen, 1998). Perhaps a heightened emotional Stroop effect in the anxiety group would have occurred had we utilised faces of fear rather than anger and disgust. On the other hand, anger and disgust faces convey direct social threat, whereas fear faces communicate indirect threat.

Also, we followed researchers who have utilised dot-probe studies involving facial expressions of anger with anxious adults, and these have often resulted in the predicted attentional bias effects (e.g., Mogg et al., 2004). Because anxietydisordered children and adolescents have exhibited an attentional bias towards threatening words (Taghavi et al. 1999; Vasey, Daleiden, Williams, \& Brown, 1995) but away from threatening faces (Monk et al., 2006, Pine et al., 2005), further elucidation of the mechanisms at work in both the Stroop and the dot probe task are needed.

The self-pacing of the Stroop task may also have affected our ability to differentiate anxious from nonanxious individuals. Although we did not collect data on how these groups may have differed in their pacing of the task, anxious individuals may have slowed down the presentation of threat faces, thus diminishing their concurrent anxiety, and thereby concealing between-group effects.

Finally, the heterogeneity of our sample could be considered a further limitation. Most participants presented with comorbid diagnoses and a range of anxiety disorders were represented. On the other hand, Bar-Haim et al. (2007) found that the magnitude of threat-related bias was similar across the anxiety disorders, and comorbidity mattered little.

Debate continues regarding the mechanisms underlying the emotional Stroop effect in anxious adults (Algom, Chajut, \& Lev, 2004; Chajut, Lev, \& Algom, 2005; Dalgleish, 2005; Williams et al., 1996). Whether it reflects attentional capture by 
threat cues, difficulty disengaging from threat, heightened accessibility of threatrelated concepts, emotion-provoked response competition, atypical functioning in neural substrates (Bar-Haim et al., 2007), or some combination thereof, remains uncertain. Regardless of the mechanism, if the effect reliably correlates with anxiety disorder status, then the emotional Stroop has value.

Unfortunately, matters remain even more complicated in the child anxiety disorders field. In addition to the effect being less reliably apparent in young patients, recent data suggest that anxiety-linked biases on the emotional Stroop are not necessarily related to similar biases on other tasks. For example, Dalgleish et al. (2003) found no correlation between attentional bias on the emotional Stroop task and attentional bias on the dot probe detection task among anxietydisordered children and adolescents. This study implies that these tasks measure different cognitive correlates of anxiety disorders.

In summary, two overriding goals confront clinical scientists working on cognitive aspects of anxiety disorders in children. They need to identify reliable measures of selective processing of threat cues, and to elucidate the mechanisms underlying these effects.

\section{Acknowledgments}

This research was conducted by the first author under the supervision of the second author in fulfillment of the degree requirements for Bachelor of Arts with Honors in the Department of Psychology at Harvard University. We thank Diego A. Pizzagalli who served as second reader, and Russell Constantine for his computer software expertise. Testing of participants occurred in the third author's Child and Adolescent Anxiety Clinic, and the assistance of Jenny Allen, Julie Sposari, Lexine Stapinski, and Leigh Carpenter is gratefully acknowledged. A grant from the Harvard College Research Program, awarded to the first author, and a grant from the Australian Rotary Health Research Fund, awarded to the third author, supported this project.

\section{References}

Algom, D., Chajut, E., \& Lev, S. (2004). A rational look at the emotional Stroop phenomenon: A generic slowdown, not a Stroop effect. Journal of Experimental Psychology: General, 133, 323-338.

Bar-Haim, Y., Lamy, D., Pergamin, L., Bakersman-Kranenburg, M.J., \& van IJzendoorn, M.H. (2007). Threat-related attentional bias in anxious and nonanxious individuals: A meta-analytic study. Psychological Bulletin, 133, 1-24.

Chajut, E., Lev, S., \& Algom, D. (2005). Vicissitudes of a misnomer: Reply to Dalgleish (2005). Journal of Experimental Psychology: General, 134, 592-595.

Constantine, R., McNally, R. J., \& Hornig, C. D. (2001). Snake fear and the pictorial emotional Stroop paradigm. Cognitive Therapy and Research, 25, 757-764.

Dalgleish, T. (2005). Putting some feeling into it - The conceptual and empirical relationships between the classic and emotional Stroop tasks: Comment on Algom, Chajut, and Lev (2004). Journal of Experimental Psychology: General, 134, 585-591.

Dalgleish, T., Taghavi, R., Neshat-Doost, H., Moradi, A., Canterbury, R., \& Yule, W. (2003). Patterns of processing bias for emotional information across clinical disorders: A comparison of attention, memory, and prospective cognition in children and adolescents with depression, generalized anxiety, and posttraumatic stress disorder. Journal of Clinical Child and Adolescent Psychology, 32, 10-21. 
Dubner, A.E., \& Motta, R.W. (1999). Sexually and physically abused foster care children and posttraumatic stress disorder. Journal of Consulting and Clinical Psychology, 67, 367-373.

Ernfelder, E., Faul, F., \& Buchner, A. (1996). Gpower: A general power analysis program. Behavior Research Methods, Instruments, $\mathcal{E}$ Computers, 28, 1-11.

Goodman, R. (1997). The Strengths and Difficulties Questionnaire: A research note. Journal of Child Psychology and Psychiatry, 38, 581-586.

Hadwin, J.A., Donnelly, N., French, C.C., Richards, A., Watts, A., \& Daley, D. (2003). The influence of children's self-report trait anxiety and depression on visual search for emotional faces. Journal of Child Psychology and Psychiatry, 44, 432-444.

Harvey, A., Watkins, E., Mansell, W., \& Shafran, R. (2004). Cognitive behavioural processes across psychological disorders: A transdiagnostic approach to research and treatment. Oxford, UK: Oxford University Press.

Holle, C., Neely, J.H., \& Heimberg, R.G. (1997). The effects of blocked versus random presentation and semantic relatedness of stimulus words on response to a modified stroop task among social phobics. Cognitive Therapy and Research, 21, 681-697.

Kindt, M., Bierman, D., \& Brosschot, J.F. (1997). Cognitive bias in spider fear and control children: Assessment of emotional interference by a card format and a single-trial format of the Stroop task. Journal of Experimental Child Psychology, 66, 163-179.

Kindt, M., Brosschot, J.F., \& Everaerd, W. (1997). Cognitive processing bias of children in a real life stress situation and a neutral situation. Journal of Experimental Child Psychology, 64, 79-97.

Kindt, M., van den Hout, M., de Jong, P., \& Hoekzema, B. (2000). Cognitive bias for pictorial and linguistic threat cues in children. Journal of Psychopathology and Behavioral Assessment, 22, 201-219.

Kusche, C.A., Cook, E.T., \& Greenberg, M.T. (1993). Neuropsychological and cognitive functioning in children with anxiety, externalizing, and comorbid psychopathology. Journal of Clinical Child Psychology, 22, 172-195.

Mansell, W., Clark, D.M., Ehlers, A., \& Chen, Y.-P. (1999). Social anxiety and attention away from emotional faces. Cognition and Emotion, 13, 673-690.

Martin, M., Horder, P., \& Jones, G.V. (1992). Integral bias in naming of phobia-related words. Cognition and Emotion, 6, 479-486.

Martin, M., \& Jones, G.V. (1995). Integral bias in the cognitive processing of emotionally linked pictures. British Journal of Psychology, 86, 419-435.

Matsumoto, D., \& Ekman, P. (1989). American-Japanese cultural differences in intensity ratings of facial expressions of emotion. Motivation and Emotion, 13, 143-157.

Mazurski, E.J., \& Bond, N.W. (1993). A new series of slides depicting facial expressions of affect: A comparison with the Pictures of Facial Affect series. Australian Journal of Psychology, 45, 41-47.

Mogg, K., Philippot, P., \& Bradley, B.P. (2004). Selective attention to angry faces in clinical social phobia. Journal of Abnormal Psychology, 113, 160-165.

Monk, C.S. et al. (2006). Ventrolateral prefrontal cortex activation and attentional bias in response to angry faces in adolescents with generalized anxiety disorder. The American Journal of Psychiatry, 163, 1091-1097.

Moradi, A.R., Taghavi, M.R., Neshat-Doost, H.T., Yule, W., \& Dalgleish, T. (1999). Performance of children and adolescents with PTSD on the Stroop colour-naming task. Psychological Medicine, 29, 415-419.

Morren, M., Kindt, M., van den Hout, M., \& van Kasteren, H. (2003). Anxiety and the processing of threat in children: Further examination of the cognitive inhibition hypothesis. Behaviour Change, 20, 131-142.

Nauta, M.H., Scholing, A., Rapee, R.M., \& Spence, S.H. (2004). Development of a parent report measure of children's anxiety: Psychometric properties and comparison with child report in a clinic and normal sample. Behaviour Research and Therapy, 42, 813-839.

Pine, D.S. et al. (2005). Attention bias to threat in maltreated children: Implications for vulnerability to stress-related psychopathology. The American Journal of Psychiatry, 162, 291-296. 
Pollak, S.D., \& Tolley-Schell, S.A. (2003). Selective attention to facial emotion in physically abused children. Journal of Abnormal Psychology, 112, 323-338.

Silverman, W.K., \& Nelles, W.B. (1988). The Anxiety Disorders Interview Schedule for Children. Journal of the American Academy of Child and Adolescent Psychiatry, 27, 772-778.

Spence, S. H. (1997). Structure of anxiety symptoms among children: A confirmatory factor-analytic study. Journal of Abnormal Psychology, 106, 280-297.

Spence, S. H. (1998). A measure of anxiety symptoms among children. Behaviour Research and Therapy, 36, 545-566.

Taghavi, M.R., Dalgleish, T., Moradi, A.R., Neshat-Doost, H.T., \& Yule, W. (2003). Selective processing of negative emotional information in children and adolescents with generalized anxiety disorder. British Journal of Clinical Psychology, 42, 221-230.

Taghavi, M.R., Neshat-Doost, H.T., Moradi, A.R., Yule, W., \& Dalgleish, T. (1999). Biases in visual attention in children and adolescents with clinical anxiety and mixed anxiety-depression. Journal of Abnormal Child Psychology, 27, 215-223.

Thrasher, S.M., Dalgleish, T., \& Yule, W. (1994). Information processing in post-traumatic stress disorder. Behaviour Research and Therapy, 32, 247-254.

Vasey, M.W., Daleiden, E.L., Williams, L.L., \& Brown. L.M. (1995). Biased attention in childhood anxiety disorders: A preliminary study. Journal of Abnormal Child Psychology, 23, 267-279.

Vasey, M.W., \& MacLeod, C. (2001). Information-processing factors in childhood anxiety: A review and developmental perspective. In M.W. Vasey \& M.R. Dadds (Eds.), The developmental psychopathology of anxiety (pp. 253-277). New York: Oxford University Press.

Whalen, P.J. (1998). Fear, vigilance, and ambiguity: Initial neuroimaging studies of the human amygdale. Current Directions in Psychological Science, 7, 177-188.

Williams, J.M.G., Mathews, A., \& MacLeod, C. (1996). The emotional Stroop task and psychopathology. Psychological Bulletin, 120, 3-24. 